УДК 82.09

ББК 83.3 (3)
HOBOE СОЗНАНИЕ И НOBЫЕ

ЖАНРОВО-СТИЛЕВЫЕ ЧЕРТЫ

В АФРИКАНСКОМ ФРАНКОЯЗЫЧНОМ

РОМАНЕ В ПЕРЕХОДНУЮ ЭПОХУ

DOI: IO.22455/2500-4247-20I7-2-I-I32-I49

Аннотация: В 90-х гг. XX в. и начале следующего в конголезской и ивуарийской литературах появился новый герой, тип африканца с бифуркационной психикой, еще сохраняющей поверхностную связь с родоплеменным сознанием, но уже с растущими индивидуально-эгоистическими устремлениями. В доминирующем жанре романа-истории событийность замещается рефлексией, внутренним монологом, сближая его с литературой самопознания. Герой романа конголезца Лопеса «В поисках Африк», лицейский преподаватель в Нанте ищет только одну Африку его воспоминаний о детстве и белом отце-враче. В его сознании смешаны ценности и понятия. Он асоциален, одержим маниакальной идеей, подавленно агрессивен и, когда предъявляет себя отцу, тот умирает. В «Полях битвы и любви» ивуарийка Таджо «просвечивает» поля сознания супругов - университетского преподавателя и его белой жены. Социально пассивные, погруженные в свою «самость», они отчуждены и от социума, и друг друга. Сапиентация, расширение сферы сознания за счет научных знаний, контактов с западной культурой при одновременной ломке родоплеменного коллективистского сознания приводят в лучшем случае к отвлеченным мечтам, как любителя астрономии в романе Донгалы «Звездные мальчики». В худшем - романе «Тупик» конголезца Д. Бияулы герой-социопат оказывается в психиатрической больнице. В тупике и герой постмодернистского романа «Господин Ки» ивуарийца К. Кваюле. Лишь одному конголезцу Сони Лабу Танси удалось в стиле авангардного реализма в сатирической трилогии о Береге представить типы бифуркационного африканца во всем многообразии и создать целостную картину реальной Африки.

Ключевые слова: сознание, индивидуализм, бифуркация, сапиентация, волшебный реализм, авангардный реализм.

Информация об авторе: Нина Дмитриевна Ляховская - доктор филологических наук, доцент, ведущий научный сотрудник, Институт мировой литературы им. А.М. Горького Российской академии наук, ул. Поварская, д. 25 а, І21069 Москва, Россия.

E-mail: lyakhovskaya@mail.ru 


\section{NEW CONSCIOUSNESS \\ AND NEW GENRE: \\ A FRANCOPHONE AFRICAN \\ NOVEL OF TRANSITIONAL TIME}

This is an open access article distributed under the Creative Commons Attribution 4.0 International (CC BY 4.O)
(C) 20I7. N.D. Lyakhovskaya

A.M. Gorky Institute of World Literature

of Russian Academy of Sciences, Moscow, Russia

Received: January 19, 2017

Date of publication: March 25, 2017

Abstract: In the I990s and in the beginning of the $20^{\text {th }}$ century, Congolese and Ivorian literatures witnessed the birth of a new character, an African with bifurcated mentality that, on the one hand, keeps, at least on the superficial level, affinities with archaic consciousness while, on the other hand, is characterized by emerging individualistic and egotistic ambitions. In the mainstream genre of the novel-story, action is replaced by reflection and inner monologue that are typical of self-reflective literature. A character of the novel Le chercheur d'Afriques by a Congolese Lopes is a teacher of Nantes seeking the Africa in his childhood memories about his white father, a doctor. Various cultural values and notions merge in his consciousness. He is asocial, obsessed with one maniacal idea, and passive aggressive; when he presents himself to his father, the latter dies. Champs de bataille et d'amour by an Ivorian Tadjo represents the inner world of a married couple - a university professor and his white wife. Socially passive, obsessed with themselves, they are alienated from both the social life and each other. Widening of the mental horizon with the help of scientific knowledge and contacts with the Western culture accompanied by the simultaneous collapse of the archaic collective consciousness results at best in abstract dreaming as in the case of the astronomer in Dongala's novel Les petits garçons naissent aussi des étoile. At worst - with sociopathic behavior and madness as in the novel L'impasse by a Congolese Biyaoula where the character-sociopath ends up in a psychiatric clinic. Existential dead-end is the theme of the postmodernist novel Le monsieur Ki. Rapsodie parisiènne à sourire pour caresser le temps by an Ivorian Kwahulé. A Congolese Sony Labou Tansi was the only writer whose satirical trilogy about Beregue (fictional name) written in the style of avant-garde realism (with the use of postmodernist devices) managed to represent the types of bifurcated consciousness of the African in their diversity and create a solid picture of the contemporary Africa.

Keywords: consciousness, bifurcation, sapiention, imagology, magic realism, avantgarde realism.

Information about the author: Nina D. Lyakhovskaya, DSc in Philology, Associate Professor, A.M. Gorky Institute of World Literature of the Russian Academy of Sciences, Povarskaya 25 a, I21069 Moscow, Russia.

E-mail: lyakhovskaya@mail.ru 
В переходную эпоху (конец XX - начало XXI вв.) в двух из самых продвинутых в художественном отношении африканских литератур - ивуарийской и конголезской появился новый герой и новые жанрово-стилистические черты, трансформирующие доминирующий жанр романа-историю в роман-вымысел.

Появляются инновационные романные структуры с новым прочтением традиционных эстетических ценностей. Такие «пограничные», маргинальные формы рождались и в переходную эпоху конца XIX-начала XX вв., если вспомнить уход от эпических форм в авангардно-модернистские в европейской романистике. В современных франкоязычных африканских литературах ярким примером такого жанрово-стилевого «взрыва» формы представляется роман «Господин Ки. Парижская рапсодия с улыбкой лелеять время» (“Monsieur Ki. Rapsodie parisienne à sourir pour caresser le Temps”) ивуарийского комедиографа и прозаика Коффи Кваюле (Koffi Kwahulé, род. в г96г г.).

Самоубийство главного героя этого романа - это собственно главное событие, заключающее в себе основную идею произведения - трагедию индивидуалистического сознания. Развязка сюжета становится здесь завязкой, - это инновация в жанровой структуре произведения, задуманного как роман-история, но не ставшего им. Кваюле представил новую жанровую форму, «играющую» то в детектив, то в роман-исповедь, напоминающую некую мозаичную конструкцию, словно составленную из элементов конструктора Lego. Поначалу кажется, что автор, имитируя традиционный эпический нарратив, тщится создать полотно жизни своих земляков из родной деревни Джими, ее многолетней истории, начиная с борьбы Самори Туре с колонизаторами. 
Однако «эпичность» стремительно разрушается едкой, сугубо пристрастной, издевательски насмешливой аттестацией героем соотечественников.

Событийная конструкция сужается до внимания лишь к одному персонажу - чердачному мизантропу, ивуарийскому «отщепенцу» - реально шизофренику, чей мозг за годы учебы в Париже не выдержал болезненно травматического «выламывания» из родоплеменного, этнического, универсально-целостного сознания. Ненавидя парижан, «чужих», и презирая «своих», он сам становится «другим», в данном случае клиническим социопатом. Состоя почти из одного его монолога (наговариваемого на магнитофон), повествование начинает напоминать исповедь, перебиваемую однако диалогом то с неким господином Ки, т. е. двойником студента, то с сакральной культовой маской Предка-киноцефала. Такие псевдодиалоги известны в мировой литературе («Братья Карамазовы» Достоевского, «Доктор Фаустус» Томаса Манна), только здесь вместо черта - сакральная маска.

Исповедующийся магнитофону парижский студент, он же геройсамоубийца субъективно хочет слиться с традиционным социумом, соотечественниками из родной деревни, от которых он был оторван несколько лет, учась в Париже и не принимая ценностей Запада. У него как бы нет настоящего. Занятия в институте, визиты к врачу - для него кажимость, видимость реальности. По-настоящему реально для него только прошлое, традиционный мир. Он в нем, но не с ними, своими земляками, которых считает сумасшедшими и невежественными дураками. Ведя диалог с фантомом - сакральной традиционной маской Предка-киноцефала (в его расстроенном воображении это реальность), он по существу хочет заключить с ним сделку (и это уже индивидуалистическое нарушение традиции): принять на себя его функции, но на своих условиях - решаемой им самим готовности стать спасителем традиционного безумного мира. Однако его самосознание лишено целостности. Он постоянно сомневается, хватит ли ему сил стать моральным авторитетом для соотечественников, стать их спасителем в образе всесильной культовой маски, ведь он знает к тому же, что серьезно болен (астма и болезнь легких). Непомерные сотерические амбиции, патологическое раздвоение сознания, презрение к миру, с которым он мечтал слиться, приводят его к самоубийству.

У ивуарийского парижанина с развившимися за время учебы интеллектуальными способностями нет уже слитности с коллективным сознанием, целостно-образным мышлением его деревенских земляков. Его уничижи- 
тельные характеристики соотечественников, высокомерное к ним отношение свидетельствуют о преобладании в его сознании ощущения «Самости» (термин К. Юнга - один из архетипов коллективного бессознательного), своей уникальности, «другости», исключительности. Как пишет И.А. Герасимова в статье «Совместное мышление как искусство: опыт синергетического исследования»: «Индивидуальное сознание в сочетании аналитическим интеллектом приобретает качество обособленности, как свободы от другого, свободы для себя. Обособленность может перейти в замкнутость, характерную для автаркичной индивидуальности. Автаркичная ${ }^{\mathrm{I}}$ индивидуальность проявляется в виде индивидуализма с присущим ему эгоизмом» [3, с. I28].

Эгоизм студента-самоубийцы проявляется на бытовом уровне: он очень любезен с консьержкой в доме, но вступает в тайную интимную связь с ее дочерью, убирающейся в его комнате, попросту использует СьюЭллен, не заботясь о ее чувствах. И он мечтает вернуться в родную деревню не просто одним из прежних деревенских жителей, а спасителем, высшим моральным авторитетом.

Драматические «роды» нового - индивидуалистического сознания показала Вероника Таджо с редким у африканских писателей углубленным психологизмом, «просветив» внутренний мир влюбленных «детей разных народов» - ивуарийца Элоки и француженки Эме в романе «Поля битвы и любви» (“Champs du bataille et d'amour,” г998). При этом кажущаяся духовная общность супругов оказывается мнимой благодаря проникновению писательницы в «поля» их сознания, потаенные «ночные» уголки внутреннего мира, где вызревают индивидуальные и неодинаковые эмоции и реакции на события, происходящие за стеной их дома.

Иу этих персонажей заметна обособленность от жизни горожан. (Описан, хотя и не назван Абиджан в Кот-д’Ивуар 90-х гг. периода политической нестабильности и межэтнических конфликтов.) Связь Элоки с родственниками очень поверхностна. Он в общем погружен в себя, в свою «Самость», точно так же, как Эме. Ощущение своей единичности, отдельности в расколотом, нестабильном социуме делает их несчастными. Индивидуализация

\footnotetext{
I Avtarkia - самоудовлетворение (греч). И.А. Герасимова распространяет значение этого экономического термина (обособленность экономики одной страны от других стран) на сознание, имея в виду обособленного от других, «самодостаточного» индивидуума, асоциального и эгоцентричного.
} 
образов достигается за счет фиксирования в их самосознании нарастания разнополярных эмоций: альтруистических, солидаристских, с одной стороны, и эгонетических, с другой.

Творчество Коффи Кваюле, В. Таджо, конголезских писателей Э. Донгалы, Д. Бияулы и Сони Лабу Танси подтверждает закономерность, общую не только для развития современных литератур, но и в целом для искусства Тропической Африки. Эта закономерность проявилась в процессе «сапиентации», по выражению В.Б. Мириманова в монографии «Искусство Тропической Африки», т. е. «в расширении и дифференциации сферы сознания» [4, с. 223], в тенденции десакрализации, гуманизации и индивидуализации авторского самосознания в художественном творчестве.

Только в литературе эта закономерность проявилась в XX в. ускоренно и обусловила в конечном счете и исключительно быстрое овладение современной романной техникой, и новаторское использование устной традиции, и отражение актуальных проблем жизни африканских народов на современной стадии мирового культурно-исторического развития.

Первые признаки этого процесса «сапиентации» традиционного родоплеменного этнического сознания заметны уже в 9о-е гг., например, в романе «В поисках Африк» (“Chercheur d'Afriques,” г990) конголезского писателя А. Лопеса. Герой романа Андре Окана Леклерк на первый взгляд крепко связан с родным традиционным миром. Лицейский преподаватель в Нанте, он постоянно носит в кармане пиджака оберег, в «красном» углу его комнаты хранится экукиссон, сакральный топорик, подаренный дядей, он с нежностью вспоминает родной дом, любимую девушку Кани, лицо которой сравнивает с традиционными масками Ифе. Однако в этом традиционном мире лицо лишь одного человека подано крупным планом, лицо его биологического отца, белого коменданта, врача по профессии, Сезара Леклерка. Андре постоянно вспоминает, как отец иногда играл с местными мальчишками, лечил его самого и как однажды отплыл на пароходе в белом колониальном шлеме, бросив их с матерью.

Комплекс брошенного ребенка доминирует в сознании Андре. Читатель ничего не узнает о его работе в лицее, отношении к профессии и ученикам. Он посещает собрания землячества, но остается равнодушным к политическим спорам соотечественников. Андре одержим одной становящейся маниакальной идеей - найти отца. Идя как «ищейка» по следу отца в Африке, 
он отыскивает в архиве Министерства заморских территорий бумаги отца: давний отчет о поездке по Западной Африке до Габона, отчет о лечении глазных болезней у населения и т. д. Полученные знания расширяют сферу его сознания: он открывает Африку, которую не знал, увиденную глазами белых, ее географию, флору, фауну, болезни населения, однако «сапиентация» не делает его счастливым. На его книжной полке стоят рядом Сенгор, Сезэр, Анта Диоп, Достоевский, Андре Жид, Сартр. Однако скрещивание разнородных культурных влияний не приводит к гармоничному их слиянию в его сознании, а диалог культур - к поведенческому и психическому консенсусу.

Постоянное психическое состояние Андре - депрессия, ощущение враждебности окружающего мира, подозрительность. Не случайно даже лицо консьержки дома, где он снимает комнату, кажется ему похожим на лицо старухи-процентщицы из «Преступления и наказания» Достоевского.

Мысленная ассоциация Андре, сравнение консьержки, которая не сделала ему ничего плохого, со старухой-процентщицей, свидетельствует о его крайне раздраженном состоянии духа, подавленности, сменяющейся возбуждением. Он ходит в лицей, встречается с соотечественниками, но делает это все автоматически. На самом деле он живет не в этой реальности, а в виртуальной реальности своего прошлого. Андре ищет не Африки, а виртуальную Африку своего детства с оставшимся там отцом, белым колонизатором в колониальном шлеме и, когда совершает прорыв из виртуальной реальности, в подлинную, найдя отца и навязав ему свое присутствие, переносит сокрушительное разочарование, получив таким образом еще одну психическую травму. Андре - современный тип африканца с бифуркационным травмированным сознанием, нестабильным, сконцентрированным только на рефлексии о себе, о своих эгоистических чувствах и эмоциях, с миксиризацией ценностей, понятий, стилей поведения в попытке адаптирования к европейским социокультурным, цивилизационным ценностям.

Эта примечательная ассоциация говорит также о том, что Лопес хорошо знаком с творчеством Достоевского. Возможно, что он читал и его роман «Подросток». Но даже если и не читал, перед нами явление частичной интертекстуальности: «...представляющее каждый литературный текст отражением неуследимого множества других литературных текстов, вступающих таким образом, с его создателем, автором в неподозреваемое этим последним соавторство» [2, с. 305]. 
Разумеется, такие сопоставления корректны только в очень узких рамках: основной сюжетной коллизии, заключающейся в стремлении главного героя романа Андре, как и Аркадия в «Подростке», «обрести» отца, встретить в другом - белом, хозяине, или аристократе, барине, как Версилов, своего, родного человека, должного признать своего незаконнорожденного сына, его идентичность. Их сближает чувство со схожим «химическим» составом это и обида, оскорбленные чувства собственного достоинства, и восхищение, и осуждение, словом, мучительная любовь.

Несоразмерность, разновеликость масштабов талантов Лопеса и Достоевского не позволяет сопоставлять другие структурные элементы этих романов, как и образы главных героев.

Тем не менее даже частичная интертекстуальность свидетельствует о взаимодействии (подозреваемом или неподозреваемом) индивидуальноавторского сознания африканских писателей с текстами мировой литературы, отражающими явления бифуркационного индивидуума в переходные эпохи.

Наконец его одержимая «охота» увенчивается успехом: он находит отца, живущего в Нанте конечно с новой семьей. В финале романа при встрече отец как бы «не узнает» своего незаконнорожденного сына и не хочет говорить о своём прошлом. Но спустя несколько дней Андре узнает, что отец внезапно умер от какой-то ураганной лихорадки, а в бреду, умирая, говорил на родном для Андре местном африканском языке.

Конец романа кажется искусственным, надуманным, попросту неудачным. Финал демонстрирует, что авторский вымысел слишком примитивно превращается в клише, психологически неубедительный моральный императив: неизбежность наказания зла, безнравственности и безответственности колонизаторов, бросающих незаконнорожденных детей на произвол судьбы, в будущем не сумевших соединить в своем сознании ценности двух миров.

Более сложная структура истории с чертами фантастического вымысла в романе «Звездные мальчики» (“Les garçons aussi naissent des étoiles,” 1998) Э. Донгалы, несущем отпечаток воздействия на стиль автора волшебного реализма, в частности романа Г. Гарсия Маркеса «Сто лет одиночества».

В первой части романа главный герой изображен как фольклорный культурный герой. Имагологическая интерпретация характера, его инаковость (alterité) по сравнению с земляками очевидна: герой рождается спустя сорок восемь часов после своих братьев-близнецов, не плачет при рождении, 
левша, с рождения наделен исключительными «волшебными» свойствами: исключительной физической силой, ясновидением, мощным интеллектом. Он плоть от плоти традиционного мира, учится у марабута, становится известным знахарем. Правда, «сапиентация» его родоплеменного сознания обусловлена генетически. Отец Мишеля (крещеное имя) - школьный учитель и тоже необычный, его интересы чрезвычайно разнообразны и обширны: от полярных исследований (он мечтает доказать, что первым на Северный Полюс ступил не американец Пири, а его чернокожий спутник), астрофизики, биологии, шумеро-аккадских мифов до теоремы Ферма. Так что Мишель все равно инаковый, чужой для земляков, а позже он уже как Матапари (имя, данное матерью - Трудное Дитя на лингала) изгоняется из родного племени после того, как женится по любви и по своей воле на женщине из другого племени.

Во второй части романа черты волшебного реализма как-то рассеиваются, исчезают, а автор возвращается к соприродному ему жанру романаистории и к стилю социального реализма. Матапари попадает в городскую среду, учится, становится машинистом паровоза. Сапиентация сознания проявляется в его странном для соотечественников увлечении астрономией; слитности с новым социумом - рабочими - у него не возникает, он - один из них, но не с ними. Мечтатель и визионер, критически относящийся к современному положению на родине (строительство социализма), всепроникающей коррупции, культу личности президента, подавлению инакомыслия, он не боец. Сапиентация сознания развила инертность, привычку к рефлексии, душевному стоицизму в позиции наблюдателя и созерцателя событий.

Самым трагическим примером травматических «родов» нового индивидуалистического сознания является судьба Жозефа Гакатики из романа Д. Бияулы с «говорящим» названием «Тупик» (“l'Impasse,” г996, Большая литературная премия Черной Африки). Жозеф - пример добровольной самоизоляции по личному выбору, очень неуравновешенный, с задатками социопата. Причем видимых причин для этой драматической бифуркации нет. Он работает на заводе Мишлен в Париже, и рабочие к нему неплохо относятся. У него есть девушка, которая его любит, и ее родители-французы к нему вполне расположены. Но Жозеф никому не верит, подозревает родителей подруги в скрытом расизме. Когда он приезжает в отпуск домой в Конго, то не находит взаимопонимания и в собственной семье. Жозефа раздражает 
мать, называющая его «угольком» (он почему-то темнее своих братьев), а он ее - «тюленем», «арлекином» (у матери пятна на коже из-за какого-то заболевания). Жозеф упрекает родственников в ханжестве, они регулярно ходят в церковь, слушают мессы, а сами то и дело бегают к марабутам.

Его возмущают видимые на улицах огромные портреты классиков марксизма-ленинизма, признаки культа личности главы государства (действие в романе происходит во времена правления Мариана Нгуаби).

Когда Жозеф приходит в министерство, где работает его кузен, его возмущает лень сотрудников. Никто ничего не делает, даже машинистки не работают. Он наблюдает безработицу, нищету, проституцию малолетних и возвращается в Париж крайне раздраженным. Соотечественники, земляки кажутся ему пустыми креагурами, отчаянно подражающими в одежде и манере поведения французам. Жозеф - чужой всем, и белым, и черным, он сознает свое абсолютное одиночество, одиночество «другого», не такого, как все, и у него начинается нервный срыв, переходящий в агрессию. Жозеф попадает в психиатрическую больницу, а после курса лечения остается там работать санитаром.

Все герои перечисленных романов - маргиналы, одиночки, сконцентрировавшиеся на личных, камерных переживаниях, душевных терзаниях из-за невозможности совместить традиционные ценности с нормами морали и ценностями Запада, из-за невозможности конструктивного диалога с «другими», иными, из-за страха перед вызовами глобализации, из-за бедствий и репрессий в собственных уже независимых странах.

Но есть один совершенно необыкновенный индивидуалист, прикидывающийся «своим» человеком, или, лучше сказать, «играющий» в своего, из народа, такого, как все. Это рассказчик во всех трех романах Сони Лабу Танси (1947-I995): «Семикратное одиночество Лорсы Лопеса» (“Les sept solitudes de Lorsa Lopez,” г985), «Глаза вулкана» (“Les yeux du volcan,” I988), «Отсчет страданий» (“Le commencement de douleurs," г995). Безымянный рассказчик из народа, но не alter ego автора - отнюдь не унылый социопат, не депрессивный изгой, не отверженный от африканского социума. Напротив, он на первый взгляд самый приверженный и почтительный к нему. Из всех франкоязычных писателей Сони Лабу Танси в этом еще традиционном и уже модернизированном социуме как «рыба» в море, рыба с глазами-телескопами. И в эти сатирические зеркала-телескопы он увидел африканскую пост- 
колониальную действительность не просто без прикрас, но сняв с объектов наблюдения все слои иллюзий, штампов, клише и мифов.

В русле тенденции сапиентации он стал самым бесстрашным аналитиком африканской действительности, самым свободным от всех художественных инолитературных влияний, направлений и стилей, и от собственной устной традиции в том числе.

Его часто называют постмодернистом. Действительно, он использует многие формальные приемы постмодернизма: иронию как модус повествования, сарказм, гиперболу, гротеск, буффонаду, шарж, гэг. Постмодернистский прием - ироничная и пародийная игра со стилями. Например, несомненна пародия на волшебный реализм Г. Гарсия Маркеса в романе «Глаза вулкана», или высмеивание своего соотечественника Жоржа Нгаля, искателя «Кубка Света» в «Отсчете страданий» (пародия на Святой Грааль), его изощренных стараний создать подлинно африканский стиль, или имитация традиционного эпического нарратива во всех романах.

К постмодернистским стилевым средствам можно отнести и аллюзиативность, цитацию, травестирование, фрагментарность и т. д. Однако, нам кажется корректнее было бы определить стиль Сони Лабу Танси как авангардный реализм, одно из направлений саморазвивающегося в XX в. реализма. Его трилогия - это своего рода новаторская жанровая антиформа, объединяющая квазихронику, квазиэпопею и квазиутопию.

Объектами бичующей, тотальной «черной» сатиры Сони Лабу Танси стали не выдуманные, фантастичные, а реальные, документально зафиксированные историками процессы и эксцессы в независимых странах Африки с трагическими для их народов последствиями. Эти реалии: провал правительственных курсов на построение социализма в Гвинее, Народной Республике Конго и других независимых странах Африки, профанация идеалов национально-освободительного движения и нравственное перерождение его лидеров, военные перевороты, гражданские и межэтнические войны, репрессивные автократические режимы, конфликт «натуры» и культуры, традиции и прогресса, маргинальное положение африканских народов, насильственно втянутых в процесс глобализации, провал «десанта» Че Гевары в 1965 г. в Конго, задумавшего там организовать что-либо подобное партизанской войне в Боливии, нищета и бесправие народа и т. д. 
Все эти реальные явления, отраженные в телескопическом зеркале сатиры, представляют Берег (вымышленное название страны, где живут персонажи романов Сони Лабу Танси) как страну отчаяния, молчания и предательства, «зону бесправия» (zone de non loi), в которой происходят «девять победоносных демократических войн» («Глаза вулкана»), государственные перевороты и межэтнические конфликты. Это не только узнаваемая НРК, но и многие другие страны ойкумены.

Под анекдотическим «процессом о поцелуе» в местечке Хондо-Нут подразумевается в «Отсчете страданий» экспансия в Африку научнотехнического прогресса, мировых ноу-хау. Метисная Африка, в образе девятилетней девочки, дочери белого плутократа Артура Баноса, которую поцеловал пожилой ученый Хоскар Хана, и рада была бы «обручиться» с наукой и разумом, олицетворяемым фанатиком технологических экспериментов, термостатов, реторт, колб, микроскопов и пр. Однако технический Запад стремится использовать эту молодую, сапиентированную Африку в своекорыстных целях. После смерти мужа, вечно (фантастически) юная Банос Майя становится невестой миллиардера Насименто Педро, который вместо слов любви присылает полчища вертолетов - металлических «крабов», закрывших небо над Хондо-Нут. Сами же жители городка рассматривают союз Хоскара и Банос Майи как колдовской, противоречащий традициям, катастрофичный и проклинают их сына, открывшего иммунитет от всех болезней, немедленно возненавидимого всеми докторами, затравленного и в конце концов умершего.

Конечно, сатирическая фреска-триптих Сони Лабу Танси производит двоякое, и смехотворное, и мрачное впечатление с лейтмотивом смерти во всех романах. Бесконечные похороны, поминальные обряды, десятки жертв несчастных случаев, бытовых и заказных политических убийств, тысячи расстрелянных полицейскими забастовщиков, фантастические масштабы стихийных бедствий и эпидемии (в том числе и эпидемии СПИД, от которой умер сам писатель) - все это метафоры угроз человечеству в XX-XXI вв., метафоры возможного Апокалипсиса.

Однако макабрические с летальным переходом эпизоды (например, «расчлененка» убитой по приказу министра внутренних дел диссидентки и правозащитницы Эстины Бронзарио в «Семикратном одиночестве Лорсы Лопеса, некрофильская поэтика с грубым натурализмом, жутковато-дерзким 
физиологизмом (описание признаков «болезни голубого краба», т. е. СПИДа в «Отсчете страданий»), хотя и сходны с приемами постмодернистов, но, как нам кажется, ближе к реалистической фантастике, которая «сводится, прежде всего, к разрушению всех привычных связей, в том числе неожиданных логических («алогизмы») связей» [г, с. 98-99]. Поэтика Сони Лабу Танси напоминает стилистику фильмов-ужастиков, «nеo noir», или «треш», это антипафосная поэтика, сливающаяся с шутовской карнавализацией, призванной, по замыслу сатирика, преодолеть энтропию жизнерадостного духа африканцев, переживающих трагические времена.

Анализ рассмотренных произведений ивуарийских и конголезских писателей убеждает в том, что в процессе сапиентации развитие сознания африканцев от родоплеменного, этнического к индивидуалистическому неизбежно должно было стать драматичным. У Андре Окана, сосредоточившего все душевные силы на детских впечатлениях и комплекс брошенного ребенка, любовь к отцу приняла болезненный мстительный характер, опустошив его в конце концов. Мишель Матапари, разочаровавшись в парламентских выборах и министрах ставшей независимой родины, отказывается от активного участия в общественной и политической жизни и довольствуется созерцанием звезд. Рефлексия убила в нем пассионарность.

Жозеф Гакатика, не желающий сблизиться ни с земляками в Париже, ни с черными, ни с белыми, превращается в социопата и попадает в психиатрическую лечебницу.

Хоскар Хана и его сын, самые сапиентированные, т. е. мудрые, и самые альтруистичные из персонажей, - единственные, можно сказать, «положительные» герои трилогии Сони Лабу Танси о Береге, в одиночку противостоящие косному традиционному миру, бескорыстно преданные науке, умирают непонятыми и отвергнутые своим народом. Десакрализацию традиционного мира, религии, ритуалов, марабутов, мифологии Сони Лабу Танси посредством иронии проводит по полной программе.

Индивидуально-авторский стиль Сони Лабу Танси органичен для его мировоззрения, мировосприятия, мыслечувствия, свободного от рудиментов родоплеменного и этнического сознания. Сони Лабу Танси - самый свободный из франкоязычных африканских писателей, выражающий свое «я» независимо от властей, рыночной конъюнктуры, политических идеологов, от авторитетов как традиционалистов, так и прогрессистов (и в том числе 
литературных авторитетов), от «дыхания предков» (выражение Бираго Диона) наконец.

По-сюрреалистически ошеломляюще «декорируя», «изукрашивая» шокирующими деталями факты смерти персонажей своих романов, он провоцирует, будоражит сознание читателей, которых в XX-XXI вв. поражают уже только цифры жертв с большим количеством нулей, так что даже геноцид в Руанде в 1994 г. остался малозамеченным СМИ и мировой общественностью.

Изображение иррационально-фантастических мегакатастроф (ураганы, черные и красные дыры на небе, бесконечные дожди, землетрясения и пр.) в его романах, эти реакции природных сил тоже подчинены задаче пробудить альтруистический инстинкт людей - стремление спасти человека как биологический вид от истребления себе подобными. Сапиентация сознания Сони Лабу Танси проявилась в том, что он, четко понимая специфику настоящего, исторического времени, в котором жил и которое проживала Африка, видел горизонты будущего раздвинутыми в бесконечность, прозревая риски и угрозы, которые несет с собой глобализация, ее узколобый рационализм и меркантилизм в использовании научнотехнического прогресса и зачастую самоубийственная для человечества, экологически безответственная деятельность.

Вот почему представляется, что творчество Сони Лабу Танси шире рамок постмодернизма. Его индивидуально-авторское сознание не бифуркационное, оно пластично-гибкое, плюралистичное. Играя со стилями, вводя интертекстуальный диалог, создавая симулякры вместо «миметических» реалистических образов (политических лидеров, революционеров, диссидентов, писателей, актеров и др.), высмеивая коллективную идентичность, он тем не менее «умудряется» (и это проявление сапиентации) сказать правду о трагической действительности Африки в эпоху глобализации. Эта категория новой реальности «просвечивает» из-за маскарадных масок его персонажей. Воспроизводя эсхатологические настроения, всегда обостряющиеся в переходные, кризисные эпохи, Сони Лабу Танси «возносится» над ними не только барочным «смехом над бездной», но и, можно сказать, неоромантизмом. Гуманистическую, романтически-светлую ноту нелегко расслышать среди шумных смеховых потоков, раскатов и каскадов беспощадной телескопической сатиры конголезского автора. Единственный раз звонкая нота нежности и лиризма зависает над плотным траурно-маскарадным текстом, когда 
Хоскар (все-таки и не случайно ученый) рассказывает делегатам мэрии, уговаривающим его побыстрее жениться, о своей мечте - футурологическом проекте, об искусственном «острове, большим, чем Конго и Португалия вместе взятые, о земле без памяти, неоспоримой собственности моих потомков. И там последние на Земле станут первыми, сбросившими груз истории, налипшую грязь трех тысяч лет обманов, унижений, сделок - наш век так устал от всего этого... Вы увидите мой остров сверкающим на восходе солнца, с золотящимися травами и розами, слегка курящимся туманным утром. Вы услышите, как он шумит и сияет сквозь восхитительные джунгли, бегущие лианы, зеленое пламя листвы» [9, р. І03].

Это ведь завещание Сони Лабу Танси, завещание «пересмешника» не только своим соотечественникам, но и всем людям Земли, завещание тем более доброе, милосердное, что сам он в то время, когда писал эту книгу, уже ни на что не надеялся, зная, что умирает. И тем не менее призвал смехом преодолевать все невзгоды, горести и страдания и мечтать о том времени, когда на Земле людей не будет войн, насилия, эпидемий и ее красота не будет уничтожена ни стихийными, ни техногенными катастрофами.

От авторов перечисленных романов Сони Лабу Танси отличает не просто высокая степень, «масштабность» фантазии, воображения и сапиентации. Неповторимость стиля, небывалость формы связана с его индивидуальностью, спецификой индивидуального сознания, соединяющего аналитический интеллект с интуицией художника. Индивидуальное сознание Сони Лабу Танси соответствовало, было коррелативно, соотносилось со временем, в котором жила Африка во второй половине XX в. - временем когнитивной эволюции, большого скачка в области культуры и теоретического научного знания, к сожалению, не сопровождавшегося адекватным скачком в области экономики и социальной сфере. Индивидуальное сознание Сони не страдает от обособленности, оно «открыто» опознанию смыслов и связей современной мировой культуры и цивилизации.

Несмотря на очевидные постмодернистские стилевые приемы (литературная игра со стилями, «спрятывание», «утаивание» своего «Я», фантастический гротеск, тотальная пародия), множественность критических смыслов в его новаторской квазиполижанровой романной структуре, главный смысл ясен в смеховой трагикомической оболочке. Писатель стремился сказать правду о непрекращающейся и после завоевания независимости африканской 
трагедии, пытаясь связать историю своей страны с Большой историей (термин, употребляемый В.В. Шервашидзе в книге «Реальность и время во французской литературе: от декаданса к современности». М., 2015), с глобальной цивилизацией, ее вызовами и смертельными угрозами.

Демифологизация устной традиции, гиперболизация и гротесковая карнавализация сущностных и, можно сказать, типичных сторон и черт африканской действительности - это все печать подлинности картины африканского мира в творчестве выдающегося конголезского писателя Сони Лабу Танси. 


\section{Список литературы}

I Бахтин М.М. Эпос и роман. СПб.: Изд-во «Азбука», 200о. 30 с с.

2 Бочаров С.Г. Сюжеты русской литературы. М.: Наука, І999. 632 с.

3 Герасимова Н.А. Совместное мышление как искусство: опыт философскосинергетического исследования // Синергетическая парадигма. Нелинейное мышление в науке и искусстве. М.: Прогресс-Традиция, 2002. 496 с.

4 Мириманов В.Б. Искусство тропической Африки. М.: Искусство, I986. 3Іо с.

5 Biyaoula D. L'impasse. P.: Seuil, r998. I64 p.

6 Dongala E. Les petits garçons naissent aussi des étoiles. P.: Serpent à plumes, I998. 3I7 p.

7 Lopes E. Le chercheur d'Afriques. P.: Seuil, I990. 236 p.

8 Kwahulé K. Le monsieur Ki. Rapsodie parisiènne à sourire pour caresser le temps. P.: Gallimard, 20IO. I46 p.

9 Sony Labou Tansi. Le commencement des douleurs. P.: Seuil, I995. I55 p.

Io Tadjo V. Champs de bataille et d'amour. P.: Presence Africaine, I996. I46 p. 


\section{References}

I Bakhtin M.M. Epos I roman [Epic and novel]. St. Petersburg, Azbuka Publ., 2000. 30I p. (In Russ.)

2 Bocharov S.G. Siuzhety russkoi literatury [Themes of Russian literature]. Moscow, Nauka Publ., 1999. 632 p. (In Russ.)

3 Gerasimova N.A. Sovmestnoe myshlenie kak iscusstvo: opyt filosofsko-sinergeticheskogo issledovaniia. Sinergeticheskaia paradigma. Nelineinoe myshlenie v nauke i iskusstve [Joint thinking as art: experience of philosophical and synergetic study. Sinergetic Paradigma. Nonlinear thinking in science and art]. Moscow, Progress-Tradition Publ., 2002. 496 p. (In Russ.)

4 Mirimanov V.B. Iskusstvo tropicheskoi Afriki [African art]. Moscow, Iscusstvo Publ., I986. 3 Io p. (In Russ.)

5 Biyaoula D. L’impasse. Paris, Seuil, I998. I64 p. (In French)

6 Dongala E. Les petits garçons naissent aussi des étoile. Paris, Serpent à plumes, I998. 317 p. (In French)

$7 \quad$ Lopes E. Le chercheur d'Afriques. Paris, Seuil, I990. 236 p. (In French)

8 Kwahulé K. Le monsieur Ki. Rapsodie parisiènne à sourire pour caresser le temps. Paris, Gallimard, 20IO. I46 p. (In French)

9 Sony Labou Tansi. Le commencement des douleurs. Paris, Seuil, I995. I55 p. (In French)

Io Tadjo V. Champs de bataille et d'amour. Paris, Presence Africaine, I996. I46 p. (In French) 